\title{
MODELS FOR BALANCED DEVELOPMENT OF BULGARIAN RURAL REGIONS IN THE CONTEXT OF CAP POST-2020
}

\author{
R. Beluhova-Uzunova*, K. Hristov \\ Department of Economics, Agricultural University - Plovdiv, Plovdiv, Bulgaria
}

\begin{abstract}
The development of rural regions and rural disparities are the main issues in the European Union regional policy. The topic continues to be an object of serious discussion among policymakers and scientist. Agriculture plays an important role in rural areas and contributes to generating employment and income. In the past decades, the CAP is reforming and changing to address the challenges in the EU rural regions. The aim of the study is based on the socio-economic analysis of the rural regions in Bulgaria to formulate opportunities for more balanced and sustainable development. The paper observes possibilities and prospects for the rural areas in Bulgaria in the context of the CAP post-2020. The study reveals that depopulation and marginalization of rural regions remain major issues in Bulgaria. Therefore, the implementation of the territorial and local model should dominate in Pillar II for the 2014-2020 programming period. These approaches could stimulate transformations and transition to sustainable regional development. In order to maximize the potential of the Pillar II funding, the national regional policy also should be reviewed.
\end{abstract}

Key words: economic growth, rural areas, financial support

\section{INTRODUCTION}

The development of rural regions in the EU is an object of serious debate related to the nature of the changes and the approaches implemented by the Common agricultural policy in this context. Rural territories face a number of challenges, which have been discussed widely.

The aim of the study is based on the socioeconomic analysis of the regions in Bulgaria to formulate opportunities for more balanced and sustainable development.

The paper observes possibilities and prospects for the rural areas in Bulgaria in the context of the CAP post-2020. The survey is based on the theoretical framework presented by Hodge and Midmore (1) and adapted to the characteristics of Bulgarian rural areas.

\section{MATERIALS AND METHODS}

There is no internationally accepted definition

Correspondence to: Rositsa Beluhova-Uzunova, Department of Economics, Agricultural University - Plovdiv, 12 Medeleev Bld., 4000 Plovdiv, Bulgaria,e-mail: rosicab_uzunova@abv.bg of a "rural area" and there are debates about the concept. While a low population density is a common starting point, it is recognised that "rurality" is a multi-dimensional concept with different meanings for different purposes (2). OECD has developed a specific definition with a focus on international comparability (3). On the other hand, Eurostat (4) urban-rural typology classifies NUTS-3 regions into three groups: predominantly rural, intermediate, and predominantly urban.

The debate on structural and political changes in rural areas remains an object of growing interest. There are several international working groups and forums that explore the central role of rural transformation (5). Although the definitions differ, regional transformation is seen as a process that contributes to the dynamics in rural areas and does not always lead to sustainable development (6). Berdegué's et al. standard definition takes rural communities as a starting point: "Transformation in rural areas can be defined as a process of comprehensive social change in which rural societies diversify their economies and reduce their dependence on 
agriculture."(7). A more general definition is given by Rauch et al. as "a long-term multidimensional process of changing the key characteristics of the economic and social life of the rural population" (8). These definitions emphasize the long-term nature of the processes of structural change in rural areas and highlight that they are related to both national and global dynamics. Despite the different definitions, there is a consensus that rural transformation is a complex process. The effect of this process extends beyond the transformation of the agricultural sector and even beyond economic transformation.

Although rural transformation may lead to diversification of rural economies and economic growth, in reality, this growth is still unequal. Furthermore, the lower share of the agricultural sector in GDP does not lead to a larger share of production, which has been conceived as an engine of sustainable economic growth. Rural disparities are considered as a significant challenge and remain key issues in the European Union regional policy.

Due to the complexity of the problem, rural development can no longer be seen only in the context of rural development programs and without taking into account the dynamics of urban centers. In order to overcome the marginalization and depopulation, governments try to develop innovative strategies aiming to make rural areas attractive places with future prospects.

Hodge and Midmore present a theoretical framework related to approaches of rural policy and indicators for rural analysis and evaluation. (1) This study is based on their survey and adapted to the characteristics of Bulgarian rural areas and the aspects of the CAP post-2020. The data is provided by the National Statistical Institute and Eurostat. (9, 10)

\section{SOCIO-ECONOMIC ANALYSIS OF BULGARIAN REGIONS}

The gross domestic product is a key measure related to economic development (11). Figure 1 presents GDP per capita in the NUTS 2 regions compared to the indicator at the national level. During the period 2014-2020, almost one-third of the EU's total budget has been devoted to cohesion policy: National and regional accounts are important in this context (12).

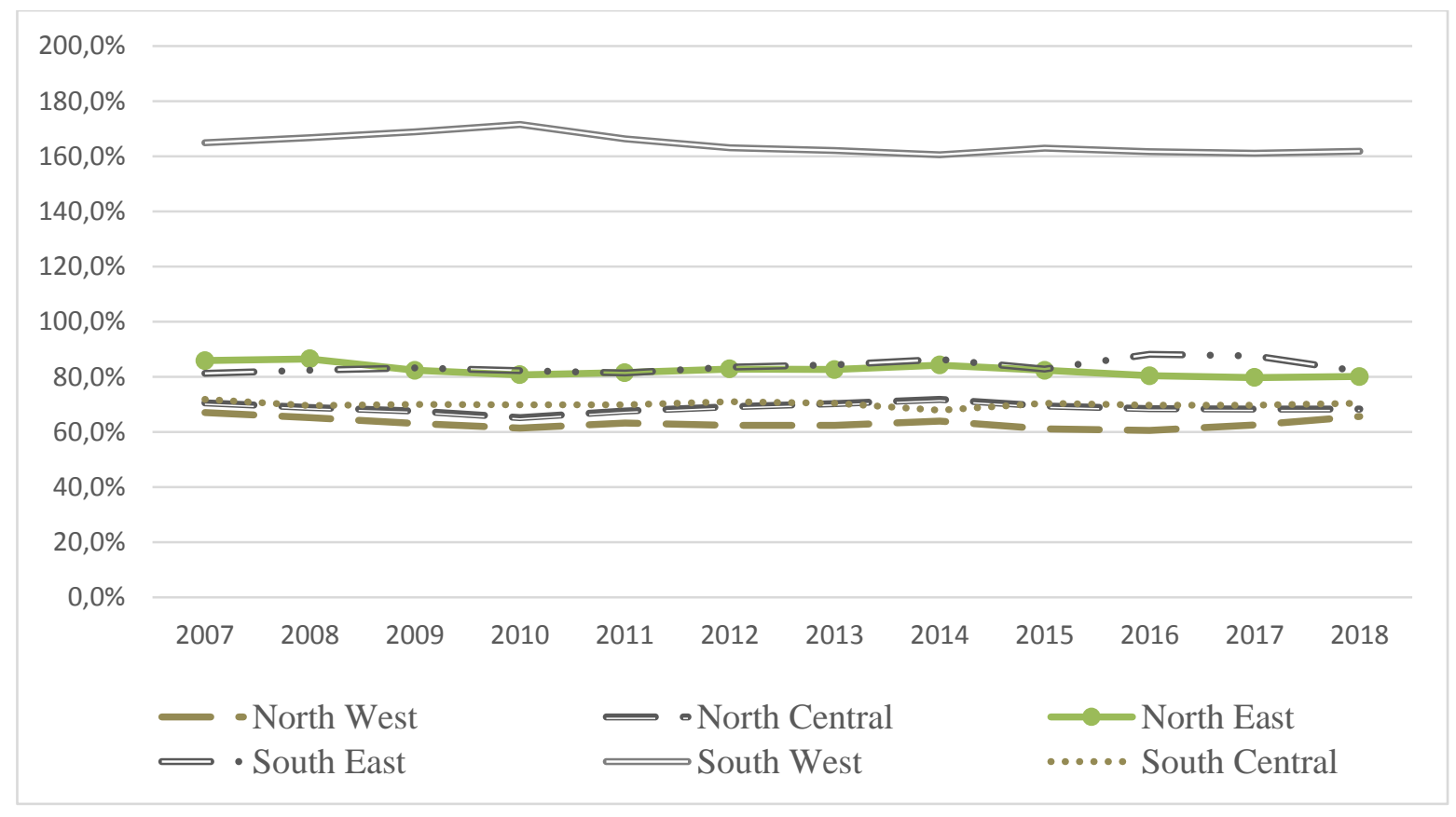

Figure 1. GDP per capita in the NUTS 2 regions $($ BULGARIA $=100 \%)$

Source: (9)

According to NSI data Gross domestic product per capita in the period from 2013 to 2018 is growing slightly faster than the EU average.
Despite the increase, all Bulgarian regions, with the exception of the South West region remain in the last place among the EU 
Member-States based on this indicator. It should be outlined that there is a significant decrease in the population of these areas during the analyzed period. Although there is Cohesion policy, as well as other financial funds, Bulgaria could not use the potential of the support and reach levels close to the EUaverage.

The results show high levels of GDP per capita in the South West region, which is with more than $69 \%$ higher than the national average. On the other hand, the North-West region represents only $65 \%$ of the national indicator. The GDP per capita in the other NUTS 2 regions varies between $70 \%-80 \%$ of the national levels. Results are also low in the South Central region, where Plovdiv, the second largest city in Bulgaria, is located. It should be noted, however, that there are also areas in the region such as Kardzhali and Smolyan with lower results.
The data show significant issues in a large part of the country's rural areas. The investments and production potential are concentrated predominantly in Sofia district while the rest of the country is lagging behind. There are clear imbalances within the regions as well. Extremely low levels of GDP per capita are registered in the North West and North Central regions. In each region is formed both: areas which are centers of economic growth and territories on the periphery with low economic development.

Another interesting comparison is related to the social indicator unemployment rate. Unemployment can have an impact not just on the economic performance of a country but also on the well-being of unemployed and on their families. (12)

Figure 2 presents the unemployment rate in the cities and in the villages in Bulgaria, as well as NUTS 2 regions with the highest and lowest levels of the indicator.

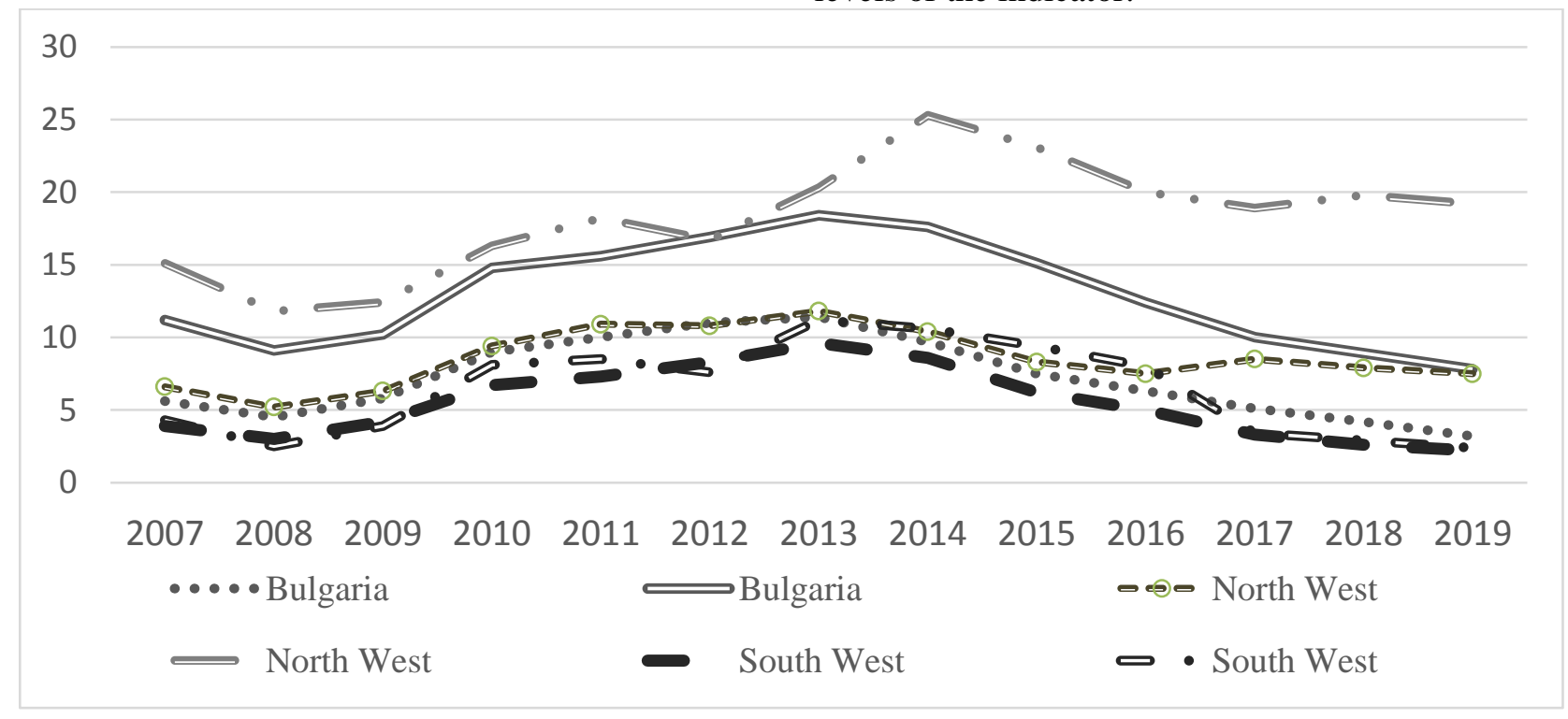

Figure 2. Unemployment rate (\%)

Source: (9)

The analysed period covers two stages of the Bulgarian economy development - the recession from 2008 to 2014 and the period after 2014 associated with stabilization on the labour market. Therefore the unemployment rate decreases gradually after 2014 due to the economic growth and macroeconomic stability. The difference between the unemployment rate in cities and villages is 4.6\% in 2019 at the national level. The highest difference is registered in the North West region -11.5 percent points, while in the South West the indicator is only 0.2 percent points.

Despite the economic growth after 2014, the differences between regions and between rural municipalities are increasing. The North West region, the North Central and the South East region remain the territories with a higher unemployment rate. The negative dynamic on labour market between 2009 and 2013, as a result of the economic and financial crisis, has affected rural areas. Despite the increase of 
employment in rural areas after 2014, there are municipalities with extremely low economic development where the unemployment rate continues to be on high levels.

Another important indicator related to rural development is the risk of poverty and social exclusion. One of the five headline targets of the Europe 2020 strategy is to reduce poverty (13).

Table 1 presents risk-of-poverty rate in NUTS 2 regions compared to national and EU-28 average.

Table 1. Risk-of-poverty rate (\% of the population), NUTS 2 regions

\begin{tabular}{|l|r|r|r|r|r|r|r|r|r|r|r|}
\hline \multicolumn{1}{|c}{$\begin{array}{c}\text { Regions/ } \\
\text { Countries }\end{array}$} & 2009 & 2010 & 2011 & 2012 & 2013 & 2014 & 2015 & 2016 & 2017 & 2018 & 2019 \\
\hline North West & 53 & 53.3 & 53.9 & 52.6 & 52.8 & 46.1 & 44.8 & 46 & 46.7 & 44.4 & 41.2 \\
\hline North Central & 56.3 & 58.7 & 59.5 & 53.9 & 48.4 & 43.7 & 44.9 & 44.3 & 41.6 & 31.7 & 35 \\
\hline North East & 45 & 52.7 & 52.1 & 51 & 53.4 & 45.6 & 48.3 & 44.1 & 42.7 & 37.3 & 34.3 \\
\hline South East & 47.8 & 51.1 & 53.2 & 56.7 & 51.1 & 41.2 & 42.5 & 42.4 & 40.1 & 34.2 & 36.5 \\
\hline South West & 33.8 & 36.9 & 37.4 & 39.1 & 37.1 & 28.6 & 30 & 30.1 & 29.3 & 23 & 22.6 \\
\hline South Central & 52.5 & 54.3 & 51.6 & 52.6 & 54.2 & 46.9 & 48.6 & 46.2 & 43.8 & 37.9 & 37.3 \\
\hline Bulgaria & 46.2 & 49.2 & 49.1 & 49.3 & 48 & 40.1 & 41.3 & 40.4 & 38.9 & 32.8 & 32.5 \\
\hline EU-28 & 23.3 & 23.8 & 24.3 & 24.8 & 24.6 & 24.8 & 24.4 & 23.8 & 23.5 & 22.4 & 21.8 \\
\hline
\end{tabular}

Source: $(9,10)$

The risk of poverty or social exclusion remains high for a number of EU Member States. According to Eurostat data, more than a third of the population was at risk of poverty or social exclusion in three EU Member States: Bulgaria, Romania, and Greece (10). For the last 10 years the rate in the EU-28 has decreased by 1.5 percentage points, in Bulgaria - by 13.7 percentage points. In general, the poverty rate decreases due to macroeconomic and financial stability and new employment opportunities.

This reduction, however, is the most significant in the North Central (21 percentage points) and South Central (15.2 percentage points) regions. On the other hand, serious regional differences in the indicator can be outlined. In the North West region, poverty is a significant social problem. The share of the population at risk of poverty or social exclusion is the lowest in the South-West region $(22.6 \%)$. The risk at the poverty rate is $47.4 \%$ in Bulgarian rural areas, more than 23 percentage points higher than EU-28 (23.7\%).

Rural areas in Bulgaria have the highest share of people at risk of poverty among the EU Member States. The unequal distribution of people at risk, however, shows a differentiation in income between rural and urban areas. Unemployment, low income, low level of education, exclusion from the labour market and economic activity are key factors for the observed trends.

Based on the analysis, it can be concluded that there is a great contrast in the development of the capital Sofia, the South West region, and other territories. The uneven distribution increases the pressure on certain resources in the regions with over-concentration of people, infrastructure, and activities. On the other hand, large parts of rural regions remain with unfulfilled economic potential.

Agriculture plays an important role in rural areas. According to the National Statistical Institute for the period 2013-2019, the agricultural sector has the highest relative share in the North West (12.4\%) and North Central (9.9\%) regions. These regions are characterized by depopulation and low economic development. However, the data suggest the importance of agriculture as a source of income and employment opportunities.

There is a gap between urban and rural areas, which hinders the modernization, 
diversification, and implementation of new technologies and affects competitiveness and sustainability in these regions. The emerging issues in rural areas influence the ability to fully explore the potential of new value chains such as clean energy, emerging bioeconomy, and the circular economy, both in terms of economic growth and sustainability. The CAP of the EU after 2020 is aiming to address some of these challenges.

\section{BALANCED REGIONAL DEVELOPMENT IN THE CONTEXT OF CAP POST 2020}

The revision of CAP regulations after 2020 can lead to better targeting and more effectiveness of financial support. There are various studies related to the institutional modelling of changes in the CAP and the impact on the structure of agriculture and rural areas (14-16) In scientific literature different views on rural development and related policy approaches known as "paradigms" are observed. Hodge and Midmore (1) present four predominant models of rural development - a sectorial postwar model, multisectoral policy with focus on agriculture in combination with support for diversification of rural economy. The territorial approach is related to wider cooperation within the rural economy and the local model takes into consideration the differentiation between rural areas and the difference within the regions and local specifics.

There is a serious emphasis on territorial approaches, also on the bottom-up approach and/or endogenous forms of governance (1719). The key features of "local" and "integrated" rural development are increasingly popular according to OECD. (20) According to some studies, however, the Rural Development Program does not recognize as a priority rural areas of the new Member States $(21,22)$. Recent discussions have pointed out the need of progress in a number of areas that have the potential to increase the contribution of rural areas to national growth. (23)

The CAP reform in 2013 could not meet the high expectations. Matthews (24) emphasizes that there are several groups dissatisfied for various reasons: environmental activists are disappointed with the results of the greening; farmers continue to seek less regulation of agricultural practices and stronger territorial measures.
Le Foll (25) and Vogelzang et al. (26) make different assumptions about the current rural development policy. Based on their study and adapted to the Bulgarian characteristics of rural areas, four models for rural development can be outlined:

Model 1: Sectorial approach - Strong focus of rural development measures and enhanced internal coherence of agricultural policy. This model is related to the post-war period and does not correspond to global trends. The high budget costs and food surpluses make this approach inappropriate for both Bulgarian and the other EU regions.

Model 2: Pillar 2 framework for the period 2014-2020 with minor changes and more simplification. Based on the European Commission proposal, it can be concluded that this model is most likely to be implemented in the next programming period. Unfortunately, in Bulgaria it has led to a concentration of support in certain sectors and regions and has not contributed to balanced regional development.

Model 3: Territorial approach under Pillar 2 Reorientation of rural development measures towards an "integrated approach" and achievement of the objectives of sectorial and territorial policies. This approach means focus on rural areas and improvement of infrastructure and employment opportunities. However, in Bulgaria some issues related to the administrative capacity and project management are observed. These issues suggest some limits to territorial approach, especially the simple distinction between urban and rural areas. The regional opportunities will depend more on local characteristics, especially the natural and economic environment.

Model 4: Local model - Adoption of a new conceptual framework that addresses the specific needs of rural areas by redirecting measures to inclusive growth and local initiatives. In Bulgaria this model could resolve some of the issues due the significant interregional differences. However, it requires administrative capacity, decentralization and coordination. Local institutions would have an important role in dealing with the policy implementation by building social capital, networks and coordination of different activities. This approach will require new vision and serious administrative restructuring at national level. 
According to some authors (27) that analyzed different reforms options, the changes in rural development policy are highly dependent on other instruments of the CAP and radical changes in the conceptual framework are very difficult to be achieved.

\section{CONCLUSIONS AND RECOMMENDATIONS}

Based on the analysis some conclusions and recommendation could be drawn:

(1) The results indicate serious differences: between Bulgaria and the EU-28 ; between the different regions in Bulgaria and intraregional differences

(2) There are measures and options under Pillar 2 of the CAP to overcome these differences

(3) There is untapped potential in the implementation of various rural development measures.

(4) An important goal after 2020 is to strengthen the role of Pillar 2

(5) Simplification of the procedures and implementation of the measures are really substantial, especially for Pillar 2

Based on the analysis, it can be concluded that regional development policy priorities and measures could help Bulgaria to overcome the emerging issues in rural areas. However, the current support under Pillar II is limited and not effectively targeted. Therefore, the focus should be revised and redirected to local specifics and assets.

It is necessary to broaden the policy vision and to include non-agricultural policies, because many additional activities are important for rural areas and affect the employment of these regions. In the context of Bulgaria, this means better coordination and interaction between ministries, agencies, local authorities and groups towards rural development goals.

\section{ACKNOWLEDGMENTS}

This paper was supported by project "Innovative models for enhancing the competitiveness of agricultural farms in Bulgaria - AGROIN", financed by the National Fund for Scientific Research at the Ministry of Education and Research.

\section{REFERENCES}

1. Hodge, I., Midmore, P., Models of Rural Development and Approaches To Analysis Evaluation And Decision- Making. Economie rurale, 307 , 23-38, 2008
2. OECD, OECD Regional Outlook 2016: Productive Regions for Inclusive Societies. OECD Publishing, Paris, 2016, https://doi.org/10.1787/9789264260245-en.

3. OECD, OECD Regional typology, https://www.oecd.org/gov/regionalpolicy/OECD_regional_typology_Nov2012 .pdf., 2011

4. Eurostat (n.d.), Urban Rural Typology, ii explained/index.php/Urban-rural_typology (accessed 20 June, 220).

5. International Fund for Agricultural Development (IFAD), Rural Development Report 2016- Fostering Inclusive Rural Transformation. Rome, Italy, September 2016, ISBN 978-92-9072-680-7

6. Atanasov, D., Popova, B., Approaces to selection and integration of indicators for sustainable development of agriculture. Trakia Journal of Sciences, Vol. 8, Suppl. 3, pp 133-139, 2010

7. Berdegué, J., Proctor, F.J., Cazzuffi, C., Inclusive Rural-Urban Linkages. Working Paper Series $n^{o}$ 123, Santiago de Chile ,2014 : http://www.rimisp.org/wpcontent/files_mf/ files_mf/1421411559123_InclusiveRural_ UrbanLinkages_edited.pdf

8. Rauch, T. et al. Ländlicher Strukturwandel in Subsahara Afrika, SLE Discussion Paper $01 / 2016$

9. National Statistical Institure, Statistic yearbooks 2007-2019

10. Eurostat, Statistics on income, social inclusion and living conditions Available at :https://ec.europa.eu/eurostat/databrowser/v iew/tessi010/default/table?lang=en Accessed 22/06/2020)

11. Zlatinov, D., Macroeconomic Challenges for the Transition to the Economy 4.0 in Bulgaria. The Scientific Papers of the University of National and World Economy, Issue 3, 2018, pp. 153-163

12. European Commission, Eurostat regional Yearbook 2019 Edition, Luxembourg: Publications Office of the European Union, 2019

13. European Commission, Brussels, 3.3.2010 $\operatorname{COM}(2010) 2020$ COMMUNICATION FROM THE COMMISSION EUROPE 2020 A strategy for smart, sustainable and inclusive growth, 2010

14. Erjavec, E., et al., Research for AGRI Committee - The CAP Strategic Plans beyond 2020: assessing the architecture and governance issues in order to achieve the 
EU-wide objectives. Brussels, European Parliament (see this study Part I), 2018

15. Matthews, A., The EU's Common Agricultural Policy Post 2020: Directions of Change and Potential Trade and Market Effects, Geneva: International Centre for Trade and Sustainable Development (ICTSD), 2018

16. European Parliament, Research for Agri Committee - CAP reform Post-2020 Challenges in agriculture, Brussels, European Union, 2016.

17. Copus, A., Shucksmith, M., Dax, T. and Meredith, Cohesion Policy for rural areas after 2013: A rationale derived from the EDORA project (European Development Opportunities in Rural Areas), ESPON 2013 Project 2013/1/2. Studies in Agricultural Economics 113 (2), 121-132. http://dx.doi. org/10.7896/j.1113

18. Shishkova, M. . Social Network Analysis of the Organizations Implementing Leader Approach in Bulgaria. Bulgarian Journal of Agricultural Economics and Management, Vol. 3, pp. 35-39, 2017

19. Georgiev, M., Roycheva, A., New institutional economics and methods for measuring the adaptation of Bulgarian agriculture. Trakia Journal of Sciences, Vol. 15, Suppl. 1, Pages 199-205, 2017

20. OECD, The New Rural Paradigm: Governance and Policy, Paris: OECD, 2006

21. Gorton, M., Hubbard, C., Hubbard, L, The Folly of the European Union Policy Transfer: Why the Common Agricultural Policy (CAP) Does Not Fit Central and
BELUHOVA-UZUNOVA R., et al.

Eastern Europe. Regional Studies, 43(10), 1305-1317, 2009

22. Manolova, V., Penov, I., The impact of policies on fruit production sectorachievements and lessons for the next programming period, Scientific Works, vol. LIX, 2015, Academic Publishing Houseof the Agricultural University - Plovdiv, 2015, ISSN 1312-6318.

23. OECD, New Rural Policy: Linking Up For Growth. Background Document, National Prosperity through Modern Rural Policy Conference, Memphis, USA, 2015

24. Matthews, A., Reflections on the CAP Post-2014. Chapter 19. In: Swinnen, J. (ed.), The Political Economy of the 20142020 Common Agricultural Policy, An Imperfect Storm. Brussels: Centre for European Policy Studies, 491-508,2015

25. LeFoll, S., A reformed CAP for competitive, sustainable and resilient agriculture. French contribution to the 29/31 May 2016 Informal Council on the post 2020 CAP.

26. Vogelzang, T., Berkhout, P., van Doorn, A., Jongeneel, R., Poppe, K., Smit, B. and Terluin, I., "Hacking the CAP", Options to redesign the European agricultural policy after 2020. Management-summary, LEIreport 2016-009.

27. Buckwell, A.,Where should the CAP go Post-2020? Chapter 20. In: Swinnen J (ed.), The Political Economy of the 2014-2020 Common Agricultural Policy, An Imperfect Storm. Brussels: Centre for European Policy Studies, 509-529.,2015 